Cite this: Phys. Chem. Chem. Phys., 2012, 14, 7276-7286

\title{
Photolysis, OH reactivity and ozone reactivity of a proxy for isoprene-derived hydroperoxyenals (HPALDs) $\dagger$
}

\author{
Glenn M. Wolfe, ${ }^{* a}$ John D. Crounse, ${ }^{b}$ Jonathan D. Parrish, ${ }^{a}$ Jason M. St. Clair, ${ }^{b}$ \\ Melinda R. Beaver, ${ }^{b c}$ Fabien Paulot, ${ }^{d}$ Tehshik P. Yoon, ${ }^{a}$ Paul O. Wennberg ${ }^{b e}$ and \\ Frank N. Keutsch ${ }^{a}$
}

Received 8th February 2012, Accepted 28th March 2012

DOI: $10.1039 / \mathrm{c} 2 \mathrm{cp} 40388 \mathrm{a}$

The $\mathrm{C}_{5}$-hydroperoxyenals ( $\mathrm{C}_{5}$-HPALDs) are a newly-recognized class of multi-functional hydrocarbons produced during the hydroxyl radical $(\mathrm{OH})$-initiated oxidation of isoprene. Recent theoretical calculations suggest that fast photolysis of these compounds may be an important $\mathrm{OH}$ source in high-isoprene, low-NO regions. We report experimental constraints for key parameters of photolysis, $\mathrm{OH}$ reaction and ozone reaction of these compounds as derived from a closelyrelated, custom-synthesized $\mathrm{C}_{6}$-HPALD. The photolysis quantum yield is $1.0 \pm 0.4$ over the range $300-400 \mathrm{~nm}$, assuming an absorption cross section equal to the average of those measured for several analogous enals. The yield of $\mathrm{OH}$ from photolysis was determined as $1.0 \pm 0.8$. The $\mathrm{OH}$ reaction rate constant is $(5.1 \pm 1.8) \times 10^{-11} \mathrm{~cm}^{3}$ molecule ${ }^{-1} \mathrm{~s}^{-1}$ at $296 \mathrm{~K}$. The ozone reaction rate constant is $(1.2 \pm 0.2) \times 10^{-18} \mathrm{~cm}^{3}$ molecule ${ }^{-1} \mathrm{~s}^{-1}$ at $296 \mathrm{~K}$. These results are consistent with previous first-principles estimates, though the nature and fate of secondary oxidation products remains uncertain. Incorporation of $\mathrm{C}_{5}$-HPALD chemistry with the above parameters in a 0 -D box model, along with experimentally-constrained rates for $\mathrm{C}_{5}$-HPALD production from isomerization of first-generation isoprene hydroxyperoxy radicals, is found to enhance modeled $\mathrm{OH}$ concentrations by $5-16 \%$ relative to the traditional isoprene oxidation mechanism for the chemical regimes of recent observational studies in rural and remote regions. This enhancement in $\mathrm{OH}$ will increase if $\mathrm{C}_{5}$-HPALD photo-oxidation products also photolyze to yield additional $\mathrm{OH}$ or if the $\mathrm{C}_{5}$-HPALD production rate is faster than has been observed.

\section{Introduction}

As the primary daytime oxidant, the hydroxyl radical $(\mathrm{OH})$ defines the oxidizing capacity of the troposphere. $\mathrm{OH}$-initiated degradation of volatile organic compounds (VOC) generates peroxy radicals $\left(\mathrm{HO}_{2}\right.$ and $\left.\mathrm{RO}_{2}\right)$ that feed ozone production through catalytic cycling of nitrogen oxide radicals $\left(\mathrm{NO}_{x}=\right.$ $\mathrm{NO}+\mathrm{NO}_{2}$ ). Reaction of $\mathrm{OH}$ with $\mathrm{NO}_{2}$ to form nitric acid $\left(\mathrm{HNO}_{3}\right)$ removes radicals from this system and is the main chain-terminating step in high- $\mathrm{NO}_{x}$ regions. Oxidized VOC

${ }^{a}$ Department of Chemistry, University of Wisconsin, Madison, WI,

USA.E-mail:gwolfe@chem.wisc.edu

${ }^{b}$ Division of Geological and Planetary Sciences, California Institute of Technology, Pasadena, CA, USA

${ }^{c}$ Now at National Exposure Research Laboratory, US EPA,

Research Triangle Park, NC, USA

${ }^{d}$ Division of Engineering and Applied Sciences, Harvard University, Cambridge, MA, USA

${ }^{e}$ Division of Engineering and Applied Science,

California Institute of Technology, Pasadena, CA, USA

$\dagger$ Electronic supplementary information (ESI) available: Details of $\mathrm{C}_{6}$-HPALD synthesis and identification, DHB sensitivity calculations, photolysis cross section estimation, extended modeling results and ozone reactivity data. See DOI: 10.1039/c2cp40388a can feed back into gas-phase chemistry or contribute to production of secondary organic aerosol (SOA). ${ }^{1} \mathrm{OH}$ levels can regulate new-particle formation in high-VOC regions ${ }^{2}$ and contribute to aerosol aging, ${ }^{3}$ affecting chemistry and climaterelevant aerosol properties. Additionally, $\mathrm{OH}$ controls the lifetime of methane, an important climate forcer, and assumptions regarding $\mathrm{OH}$ concentrations and chemistry can markedly perturb model predictions of past, present and future climate. ${ }^{4}$

Chemical models routinely fail to reproduce observed $\mathrm{OH}$ concentrations in regions with large biogenic emissions, often with under-predictions by factors of 2 or more. ${ }^{5-12}$ Modelmeasurement discrepancies tend to be most severe in highVOC regions dominated by isoprene (2-methyl-1,3-butadiene), a biogenic hydrocarbon with an annual global emission rate of $\sim 500 \mathrm{Tg}$ per year. ${ }^{13}$ In attempts to better understand these issues, renewed theoretical ${ }^{14-17}$ and experimental ${ }^{5,6,9,18,19}$ work on isoprene oxidation have revealed a rich chemistry previously unknown, including several mechanisms which effectively recycle $\mathrm{HO}_{\mathrm{x}}\left(=\mathrm{OH}+\mathrm{HO}_{2}+\mathrm{RO}_{2}\right)$. One such mechanism, originally proposed by Peeters et al., ${ }^{17}$ involves the isomerization and decomposition of isoprene hydroxyperoxy radicals $\left(\mathrm{ISO}_{2}\right)$ to release $\mathrm{HO}_{2}$ and a new class of products 
known as $\mathrm{C}_{5}$-hydroperoxyenals ( $\mathrm{C}_{5}$-HPALDs). It is further theorized that $\mathrm{C}_{5}$-HPALDs undergo rapid photolysis (with a presumed atmospheric lifetime of 30-180 min) to produce $\mathrm{OH}$ and an alkoxy radical, which is then predicted to further isomerize/decompose, forming $\mathrm{HO}_{2}$ and a peroxy-acid-aldehyde (PACALD). Photolysis of the PACALD is assumed to be even more efficient, leading to further production of $\mathrm{OH}$ and $\mathrm{HO}_{2}$. Incorporation of this chemistry into numerical simulations improves model-measurement agreement for $\mathrm{OH}$ in some cases ${ }^{20,21}$ but can create additional problems, such as misrepresentation of other oxidized $\mathrm{VOC}^{22}$ and over-prediction of $\mathrm{HO}_{2} \cdot{ }^{11}$

Ultimately, the impact of this mechanism on $\mathrm{HO}_{\mathrm{x}}$ abundance depends on both the rate of $\mathrm{C}_{5}$-HPALD production from $\mathrm{ISO}_{2}$ isomerization and the photolysis and $\mathrm{OH}$ reaction rates of the $\mathrm{C}_{5}$-HPALD products. Using isomerization rates derived from first principles, Peeters and Müller ${ }^{16}$ predict $\mathrm{C}_{5}$-HPALD yields of as much as $70 \%$ from summertime isoprene oxidation. More recently, a laboratory investigation by Crounse et al. ${ }^{18}$ has provided experimental evidence that the $\mathrm{C}_{5}$-HPALD production rate is 25 to 75 times slower than previously predicted. Despite the slower rate, $\mathrm{C}_{5}$-HPALD production is still predicted to make up as much as $20 \%$ of the annual average reactive flux in high-isoprene, low-NO regions; thus, its chemistry is, in places, as significant as that of methyl vinyl ketone and methacrolein and therefore should be incorporated into chemical models.
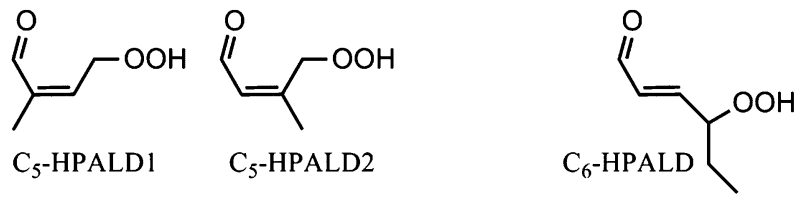

In this work, we use a synthesized six-carbon analog to $\mathrm{C}_{5}$-HPALDs to probe the photochemistry of this class of compounds. Specific experiments are aimed at assessing the photolysis quantum yield and $\mathrm{OH}$ yield, as well as the rate constants for reaction with $\mathrm{OH}$ and ozone $\left(\mathrm{O}_{3}\right)$. To our knowledge, this represents the first attempt to experimentally determine these parameters.

\section{Methods}

Four types of experiments are reported here: (1) photolysis of $\mathrm{C}_{6}$-HPALD, either with or without an $\mathrm{OH}$ scavenger, (2) reaction of $\mathrm{C}_{6}$-HPALD with $\mathrm{OH}$, either with or without $\mathrm{OH}$ tracers, (3) reaction of $\mathrm{C}_{6}$-HPALD with ozone and 4) reaction of isoprene-derived $\mathrm{C}_{5}$-HPALDs with ozone. Initial conditions and key results for these experiments are summarized in the appropriate sections.

The 1000-liter Teflon-FEP reaction chamber is described in detail elsewhere. ${ }^{18}$ All experiments were performed at room temperature $(296 \pm 2 \mathrm{~K})$ and atmospheric pressure (745 Torr, $99.3 \mathrm{kPa}$ ). UV lights along one wall of the chamber enclosure provide radiation with a peak emission at $340 \mathrm{~nm}$ as measured by a Licor spectroradiometer (LI-1800, 300-850 nm). Photolysis experiments were carried out under full illumination, giving a calculated $\mathrm{j}\left(\mathrm{NO}_{2}\right)$ of $8.4 \times 10^{-4} \mathrm{~s}^{-1}$, approximately $1 / 10$ that of natural sunlight. $\mathrm{OH}$ reaction experiments employing the photolysis of methyl nitrite $\left(\mathrm{CH}_{3} \mathrm{ONO}\right)$ as an $\mathrm{OH}$ source (R1-R2) utilized only a single shielded UV bulb, yielding $\sim 30$ times lower photon flux. Using published cross sections $^{23}$ and an assumed quantum yield of 1 with the measured photon flux gives an estimated $\mathrm{j}\left(\mathrm{CH}_{3} \mathrm{ONO}\right)$ of $0.9 \times 10^{-5} \mathrm{~s}^{-1}$ for these experiments.

$$
\begin{gathered}
\mathrm{CH}_{3} \mathrm{ONO}+\mathrm{hv} \stackrel{\mathrm{O}_{2}}{\rightarrow} \mathrm{HCHO}+\mathrm{HO}_{2}+\mathrm{NO} \\
\mathrm{HO}_{2}+\mathrm{NO} \rightarrow \mathrm{OH}+\mathrm{NO}_{2}
\end{gathered}
$$

(E)-4-Hydroperoxyhex-2-enal $\left(\mathrm{C}_{6}\right.$-HPALD) was synthesized following established techniques. ${ }^{24}$ Briefly, preparation involved oxidation of $(2 E, 4 E)$-hexadien-1-ol to its corresponding aldehyde through reaction with $\mathrm{MnO}_{2}$, followed by selective addition of a peroxide group via a custom-synthesized inorganic catalyst. Full details on the synthesis are provided in the Electronic Supporting Information (ESI). $\dagger$ NMR spectra show the purity of the condensed-phase sample to be $\sim 80 \%$. The main impurities were identified as the singly-saturated and doubly-saturated alcohol analogues of the $\mathrm{C}_{6}$-HPALD (i.e., replacing $-\mathrm{OOH}$ with $-\mathrm{OH}$ ), which are likely sideproducts of the second reaction step or the result of condensedphase decomposition. A condensed-phase UV-visible spectrum could not be obtained due to interferences from the cobaltbased catalyst, and the low vapor pressure of the $\mathrm{C}_{6}$-HPALD precludes acquisition of gas-phase UV-Vis or IR spectra by standard techniques (i.e., without a multi-pass system). $\mathrm{C}_{6}$-HPALD samples were prepared at the University of Wisconsin, frozen in benzene and shipped to Caltech on dry ice where they were stored in the dark at $-8{ }^{\circ} \mathrm{C}$ until needed. Prior to use, $\mathrm{C}_{6}$-HPALD was separated from benzene via evaporation of the solvent at $5-10{ }^{\circ} \mathrm{C}$ under vacuum ( $\sim 0.05$ Torr), leaving behind a clear yellow oil. Gas-phase $\mathrm{C}_{6}$-HPALD was added to the chamber by flowing zero air or nitrogen over the pure oil, providing initial mixing ratios of 1-50 ppbv (details on calibration in ESI).

Additional chemicals were purchased in high purity from Sigma-Aldrich and used without further purification. For experiments requiring an $\mathrm{OH}$ scavenger (HPALD photolysis and $\mathrm{O}_{3}$ reactions), an excess of phenol $\left(\mathrm{C}_{6} \mathrm{H}_{5} \mathrm{OH}\right)$ was added by flowing zero air over the pure crystals, providing initial mixing ratios of $0.5-4$ ppmv. For determination of the $\mathrm{OH}$ reaction rate constant via the relative rates technique, methacrolein (MACR) and 1,2-dihydroxybenzene (DHB) were employed as reference compounds. Gas-phase MACR standards of $\sim 300$ ppmv were prepared by evaporating a known mass of the liquid compound into a known volume of $\mathrm{N}_{2}$ in a $75 \mathrm{~L}$ Teflon bag. The concentration of MACR in these standards was determined prior to each experiment using FTIR spectroscopy with tabulated cross sections, and $50 \mathrm{~cm}^{3}$ of this calibrated mixture was transferred to the chamber via a gas-tight ground-glass syringe. DHB was added by passing zero air over the pure crystals.

Methyl nitrite was synthesized, purified and stored in liquid nitrogen following established methods. ${ }^{23}$ Purity was checked using FTIR spectroscopy. For use in experiments, $\mathrm{CH}_{3} \mathrm{ONO}$ was removed from liquid nitrogen and slowly warmed, releasing $\sim 15$ Torr of the vapor into an evacuated $500 \mathrm{~cm}^{3}$ bulb. This fill was discarded, and the bulb was filled again to 5-15 Torr. 
The bulb contents were then diluted by filling to atmospheric pressure with $\mathrm{N}_{2}$ gas and pumping down to a pressure of 5-15 Torr. The contents of the bulb were then transferred to the reaction chamber.

$\mathrm{O}_{3}$ was produced by flowing research grade $\mathrm{O}_{2}$ through an electric discharge using a commercial ozone generator (Ozmonics V10-0). The resulting $\mathrm{O}_{3}$ was trapped from the $\mathrm{O}_{3} / \mathrm{O}_{2}$ stream on clean, dry granular silica gel at $-65^{\circ} \mathrm{C}$. The ozone/silica gel was maintained below $-60^{\circ} \mathrm{C}$ using a chilled isopropanol bath. For use in experiments, a small stream of $\mathrm{N}_{2}$ was carried over the $\mathrm{O}_{3} /$ silica gel at $-60{ }^{\circ} \mathrm{C}$. The stream was used to fill a $500 \mathrm{~mL}$ bulb as well as an FTIR cell. The contents of the $500 \mathrm{~mL}$ bulb were transferred into the experiment bag, and the $\mathrm{O}_{3}$ concentration in the IR cell was measured using known IR cross-sections. ${ }^{25}$ Initial $\mathrm{O}_{3}$ concentrations ranged from 300-3000 ppbv. $\mathrm{O}_{3}$ addition marked the beginning of the experiment. $\mathrm{O}_{3}$ was continuously measured using a commercial $\mathrm{O}_{3}$ monitor (Teledyne 400E). Corrections to this measurement were made to account for the UV absorption of phenol.

For the $\mathrm{C}_{5}$-HPALD $+\mathrm{O}_{3}$ experiment, $\mathrm{C}_{5}$-HPALDs were produced within the experiment bag from isoprene $+\mathrm{OH}$ gas-phase reaction under warm, dim conditions as described previously.$^{18}$ In this case, air was not sampled from the experiment bag during the $\mathrm{C}_{5}$-HPALD production phase. After $\mathrm{C}_{5}$-HPALD production, the UV light was turned off, and the chamber was cooled to $296 \mathrm{~K}$. Phenol and $\mathrm{O}_{3}$ were added in the same fashion as described for the $\mathrm{C}_{6}$-HPALD $+\mathrm{O}_{3}$ experiment.

Dry zero air from a purge gas generator was used to fill the reaction chamber to a starting volume of 980-1000 standard liters for all experiments. After allowing $\sim 1 \mathrm{~h}$ for reactants to mix, the UV lights were energized to initiate slow photochemistry. Sampling conditions provided an effective maximum runtime of $8 \mathrm{~h}$. Between experiments, the reaction chamber was flushed 2-3 times with $\sim 500$ liters of zero air with all lights energized. Reactants and products were monitored with the Caltech triple quadrupole chemical ionization mass spectrometry (TQ-CIMS) instrument, utilizing $\mathrm{CF}_{3} \mathrm{O}^{-}$as the primary reagent ion. ${ }^{26}$ The chamber sampling setup was identical to that described by Crounse et al. ${ }^{18} \mathrm{CF}_{3} \mathrm{O}^{-}$reacts with neutral analyte molecules primarily by clustering and/or fluoride transfer, resulting in product ions at $m / z=$ mass $_{\text {neutral }}+$ $85 \mathrm{amu}$ and/or $m / z=$ mass $_{\text {neutral }}+19 \mathrm{amu}$, respectively. This chemistry is selective towards a wide range of oxygenates, including hydroperoxides, organic and some inorganic acids, hydroxynitrates and larger alcohols (e.g., phenol and DHB). The TQ-CIMS was operated in both single MS and MS/MS modes. The latter permits separation and quantification of certain isobaric ions ${ }^{16}$ and can also help elucidate the structure of unidentified ions via collisional dissociation "fingerprints" specific to certain functionalities. Certain species that could not be monitored using $\mathrm{CF}_{3} \mathrm{O}^{-}$(notably MACR) were measured using $\mathrm{H}^{+} \cdot\left(\mathrm{H}_{2} \mathrm{O}\right)_{n}$ as the reagent ion.

$\mathrm{C}_{6}$-HPALD was monitored using the $\mathrm{CF}_{3} \mathrm{O}^{-}$cluster ion at $m / z=215 \mathrm{amu}$ and quantified using calculated ion-molecule collision rates. ${ }^{27} \dagger$ The identity of this ion was further confirmed via the ${ }^{13} \mathrm{C}$ isotope ratio and MS/MS spectra. $\dagger$ Phenol was monitored using the ${ }^{13} \mathrm{C}$ isotope cluster ion at $m / z=$ $180 \mathrm{amu}$ (due to excessively high signal at the ${ }^{12} \mathrm{C}$ mass) and quantified by standard addition of a gas-phase mixture, the concentration of which was determined by FTIR spectroscopy. MACR was monitored in positive ion mode at $m / z=71$ amu and quantified using standard additions. DHB was monitored using the fluoride transfer ion at $m / z=129 \mathrm{amu}$ but could not be quantified by standard addition due to significant challenges associated with preparing gas-phase standards. A sensitivity for this compound was instead determined by a separate experiment involving the oxidation of phenol by $\mathrm{OH}$, as described in the ESI. $\dagger$ This method has consequences for the uncertainty in the measured $\mathrm{OH}$ yield from $\mathrm{C}_{6}$-HPALD photolysis, as discussed below.

Wall losses for $\mathrm{C}_{6}$-HPALD, phenol, DHB and MACR were determined by injecting these compounds into the chamber and observing their decay in the dark several times over the course of the experiments. Average first-order wall loss coefficients (mean $\pm 2 \sigma$ ) are $7.0 \pm 0.4,1.0 \pm 0.5,5.9 \pm 0.5$ and $2.5 \pm 0.7 \times 10^{-6} \mathrm{~s}^{-1}$, respectively. Measured concentration time profiles were corrected for wall loss according to

$$
[X]_{\text {corr }}=[X]_{\text {meas }} e^{k_{w} t}
$$

Where $[X]$ is concentration, $k_{w}$ is the wall loss coefficient and $t$ is experiment time.

Mass spectra indicate that some impurities in the $\mathrm{C}_{6}$-HPALD sample were also introduced into the chamber. In particular, masses observed at negative $m / z 197$ and 199 are respectively consistent with the singly-saturated and doublysaturated alcohol analogues of the $\mathrm{C}_{6}$-HPALD (i.e., replacing $-\mathrm{OOH}$ with $-\mathrm{OH}$ ) that were also observed in NMR spectra of the condensed-phase sample. The purity of the gas-phase $\mathrm{C}_{6}$-HPALD sample is estimated from the CIMS signals as $100 \times \mathrm{m} 215 /(\mathrm{m} 215+\mathrm{m} 197+\mathrm{m} 199)=80 \%$. Tandem MS/MS spectra of these parent masses show no daughter signal at $m / z 63$, a strong indication that they are not peroxides. Comparison of the time profiles of these signals with those of $\mathrm{C}_{6}$-HPALD and other reactants indicates that these compounds do not readily photolyze and thus should not impact reported $\mathrm{OH}$ yields or product distributions.

\section{Results and discussion}

\subsection{Photolysis quantum yield}

Fig. 1 shows a typical first-order decay profile for $\mathrm{C}_{6}$-HPALD photolysis. Phenol comprises $>99 \%$ of the $\mathrm{OH}$ reactivity in these experiments, implying that the observed $\mathrm{C}_{6}$-HPALD decay is not affected by reactions with $\mathrm{OH}$. The slope of the ordinary linear least squares fit of the $\mathrm{C}_{6}$-HPALD logarithmic decay thus provides a direct measurement of the photolysis rate constant. For the conditions of our chamber, the average photolysis rate constant from four such experiments (Table 1) is $(6.3 \pm 0.2) \times 10^{-5} \mathrm{~s}^{-1}$. The quoted uncertainty includes contributions from the individual fits and from the wall loss correction. Note that potential systematic uncertainties in concentration measurements (i.e., errors in computed calibration factors) do not affect this result, as data are normalized to starting concentrations.

Calculation of a photolysis quantum yield requires knowledge of the wavelength-dependent photon flux and $\mathrm{C}_{6}$-HPALD absorption cross section. The former was measured as described above. 


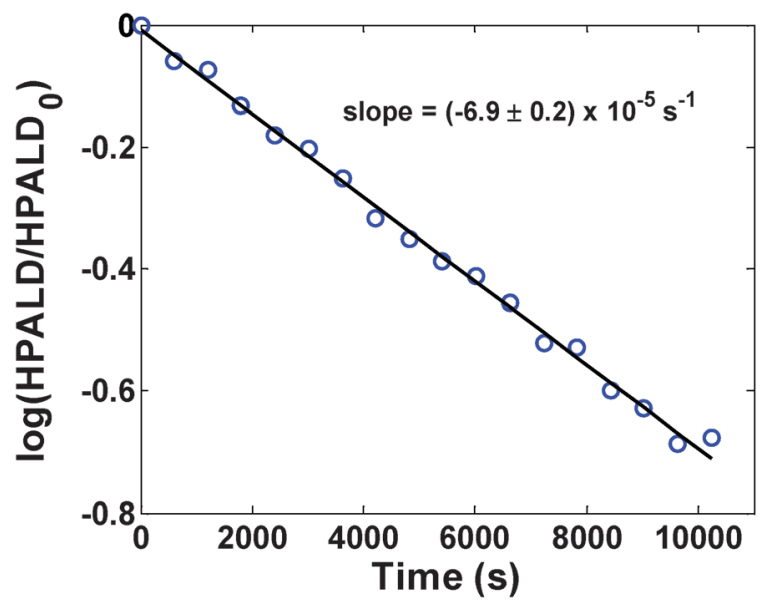

Fig. 1 Logarithmic decay of $\mathrm{C}_{6}$-HPALD from photolysis experiment PH1.

Table 1 Summary of photolysis experiments

\begin{tabular}{lcccl}
\hline Exp. & $\begin{array}{l}{[\mathrm{HPALD}]_{0}} \\
(\mathrm{ppbv})\end{array}$ & $\begin{array}{l}{[\mathrm{Phenol}]_{0}} \\
(\mathrm{ppbv})\end{array}$ & $\begin{array}{l}\mathrm{j}(\mathrm{HPALD}) \\
\left(10^{-5} \mathrm{~s}^{-1}\right)\end{array}$ & OH yield \\
\hline PH1 & 4.39 & 494 & $6.9 \pm 0.2$ & $0.95 \pm 0.05$ \\
PH2 & 1.61 & 1265 & $6.9 \pm 0.5$ & $1.39 \pm 0.19$ \\
PH3 & 1.52 & 2517 & $5.4 \pm 0.4$ & $1.76 \pm 0.34$ \\
PH4 & 3.31 & 3689 & $5.2 \pm 0.3$ & $1.05 \pm 0.13$ \\
Avg & & & $\mathbf{6 . 3} \pm \mathbf{0 . 1}$ & $\mathbf{0 . 9 7} \pm \mathbf{0 . 0 4}$ \\
PH5 & 35.6 & - & $6.5 \pm 0.1$ & -
\end{tabular}

HPALD photolysis rates are calculated as the slope of the linear leastsquares fit to the logarithmic HPALD decay from the first $3 \mathrm{~h}$ of each experiment. $\mathrm{OH}$ yields are calculated from the slope of a linear leastsquares fit of HPALD decay versus DHB growth, with the latter corrected for background $\mathrm{OH}$ production and a DHB yield of $80 \%$. Errors represent the $2 \sigma$ uncertainty in the fits, and averages are uncertainty-weighted $\left(1 / \sigma^{2}\right)$. The last experiment was performed without phenol to examine the product distribution.

Most of the UV lamp emission occurs at $350 \pm 50 \mathrm{~nm}$, with a peak emission of $3.8 \times 10^{13}$ photons $\mathrm{cm}^{-2} \mathrm{~s}^{-1} \dagger$ The low vapor pressure of $\mathrm{C}_{6}$-HPALD and the presence of lowvolatility inorganic impurities prevented a direct experimental determination of the absorption cross section from gas-phase or condensed-phase UV-Visible spectroscopy. Thus, following the rationale that radiation is primarily absorbed by the $\mathrm{O}=\mathrm{C}-\mathrm{C}=\mathrm{C}$ chromophore, we assume a cross section equal to the average of those measured for three molecules with the same chromophore (methacrolein, ${ }^{28}$ acrolein $^{29}$ and $(E)-2-$ hexenal $\left.{ }^{30,31}\right) .{ }^{32}+$ Cross sections for these compounds differ by an average of $14 \%$ over our experimental wavelength range. From these values, we estimate a bulk photolysis quantum yield of $1.0 \pm 0.4$ over the range $300-400 \mathrm{~nm}$. The uncertainty in this value includes both the uncertainty in the photolysis rate constant and a weighted-average $2 \sigma$ uncertainty of $28 \%$ from the averaged cross section. This value agrees well with the unity quantum yield estimated for the isoprene-derived $\mathrm{C}_{5}$-HPALDs. ${ }^{16}$

\subsection{Photolysis products}

3.2.1 OH. Production of $\mathrm{OH}$ from $\mathrm{C}_{6}$-HPALD photolysis was quantified from the growth of DHB, which is produced from the reaction of $\mathrm{OH}$ with phenol at a yield of $80 \pm 12 \% .^{33}$

$$
\text { phenol }+\mathrm{OH} \stackrel{\mathrm{O}_{2}}{\rightarrow} 0.8 \mathrm{DHB}+0.8 \mathrm{HO}_{2}+\text { products }
$$

Potential interferences in this experiment include loss of DHB to reaction with $\mathrm{OH}$, reactions of $\mathrm{HO}_{2}$ produced in (R3) with $\mathrm{NO}$ to regenerate $\mathrm{OH}$, and "background $\mathrm{OH}$ " produced in the chamber (e.g., from reactions on chamber walls). Loss of DHB to $\mathrm{OH}$ over the course of a typical experiment is estimated to be $<2 \%$ following a standard method. ${ }^{34}$ Production of $\mathrm{OH}$ from reaction of $\mathrm{HO}_{2}$ and $\mathrm{NO}$ cannot be calculated directly because measurements of these species are not available. $\mathrm{HO}_{2} \mathrm{NO}_{2}, \mathrm{HNO}_{3}$ and $\mathrm{HONO}$ concentrations were below the instrument detection limit during experiments, suggesting negligibly small $\mathrm{NO}_{x}$ levels. Background $\mathrm{OH}$ production was determined in a separate set of experiments by filling the chamber with 1-2 ppmv phenol and observing the growth of DHB during irradiation, yielding an average background DHB production rate of $5.5 \pm 2.3 \mathrm{pptv} \mathrm{min}^{-1}$. The large uncertainty in this value stems primarily from the uncertainty in absolute DHB mixing ratios $(42 \%)$. $\dagger$ The background $\mathrm{OH}$ production rate was assumed to be constant over the course of an experiment and applied as a correction to the DHB production rate. The yield of $\mathrm{OH}$ from $\mathrm{C}_{6}$-HPALD photolysis, $y_{O H}$, can then be written as

$$
y_{\mathrm{OH}}=\frac{\left(\Delta \mathrm{DHB}-P_{b k g d} \Delta t\right) / y_{\mathrm{DHB}}}{\Delta \mathrm{HPALD}}
$$

where $y_{D H B}$ is the yield of DHB from (R3) and $P_{b k g d}$ is the background DHB production rate.

Fig. 2 shows the "corrected" DHB production (the numerator of eqn (2)) versus $\mathrm{C}_{6}$-HPALD loss for a typical experiment. The slope of this line corresponds to the inferred $\mathrm{OH}$ yield. Table 1 summarizes the $\mathrm{OH}$ yields derived from four such experiments; the $1 / \sigma^{2}$ weighted average of these values is $0.97 \pm 0.04$. The total uncertainty in the average $\mathrm{OH}$ yield should include the weighted uncertainty from fitting (0.04), as well as uncertainties in the absolute mixing ratios of $\mathrm{C}_{6}$-HPALD and phenol and in the background DHB production rate. Uncertainty in $\mathrm{C}_{6}$-HPALD concentrations arises

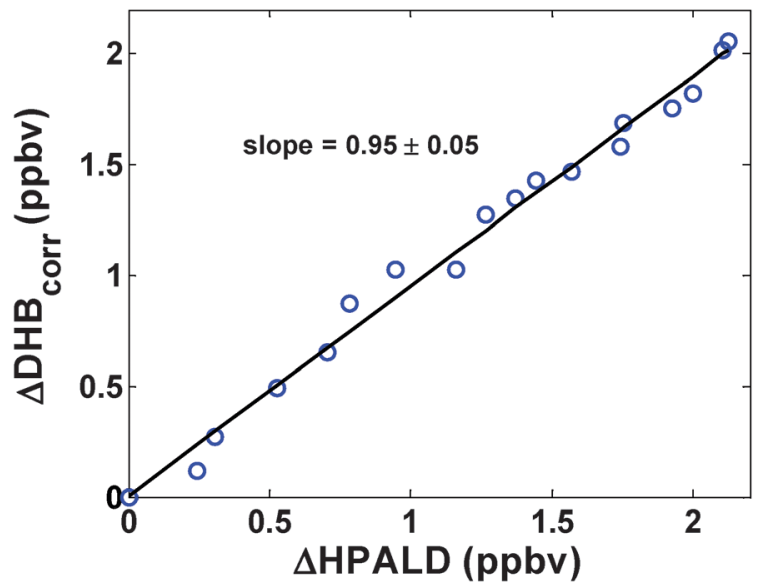

Fig. $2 \mathrm{OH}$ yield plot for the first $3 \mathrm{~h}$ of photolysis experiment PH1. DHB growth has been corrected for background $\mathrm{OH}$ and the phenol reaction yield as described in the text. 
primarily from the use of calculated ion-molecule collision rates to derive the CIMS sensitivity for this compound and is estimated to be $\pm 50 \%$. $\dagger$ The uncertainty in DHB concentrations is estimated as $42 \%$, including a $15 \%$ contribution from the uncertainty in the DHB yield. $\dagger$ Because $y_{D H B}$ appears in the denominator of eqn (2), however, a cancellation of errors effectively decreases the uncertainty in both $\triangle \mathrm{DHB}$ and $\mathrm{P}_{\mathrm{bkgd}}$ (which also relies on DHB concentrations) to $27 \%$. Combining these uncertainties gives a final estimate for the yield of $\mathrm{OH}$ from $\mathrm{C}_{6}$-HPALD photolysis of $1.0 \pm 0.8$.

3.2.2 Other products. To gain further insight on the mechanism of photolysis, a separate experiment was conducted where $\mathrm{C}_{6}$-HPALD was photolyzed in the absence of phenol to allow identification of products. The expected reaction pathways are shown in Scheme 1. After scission of the $\mathrm{O}-\mathrm{OH}$ bond, the resulting alkoxy radical should either rapidly decompose in the presence of oxygen to create fumaraldehyde (trans-2-buten-1,4-dial) and ethyl peroxy radical (upper channel) or react with $\mathrm{O}_{2}$ to make $\mathrm{HO}_{2}$ and a $\mathrm{C}_{6}$ dicarbonyl (lower channel). Scission of the $\mathrm{C}_{3}-\mathrm{C}_{4}$ carbon bond to generate propanal and a vinyl radical is an alternative pathway, but this channel is energetically less favorable and therefore likely minor. ${ }^{35}$ In a low-NO environment, the ethyl peroxy radical will react with $\mathrm{HO}_{2}$ to form ethyl hydrogen peroxide. Self-reaction or reaction with other $\mathrm{RO}_{2}$ is also a possibility, though kinetic modeling of this experiment, constrained by the observed $\mathrm{H}_{2} \mathrm{O}_{2}$ production rate, suggests this channel should comprise less than $2 \%$ of the total ethyl peroxy radical loss. The growth of a signal at negative $m / z$ 147, observed during this experiment, may correspond to the cluster ion of ethyl hydrogen peroxide $(62+85)$. Using the calibrated sensitivity to methyl hydrogen peroxide ${ }^{26}$ to convert this signal to a concentration gives an estimated yield of $9 \%$. Neither fumaraldehyde nor the $\mathrm{C}_{6}$-dicarbonyl were observed in positive or negative ion mode, though without an authentic standard it is unknown if the CIMS is sensitive to these compounds. With the present dataset, we cannot provide a firm conclusion regarding the nature or fate of $\mathrm{C}_{6}$-HPALD photolysis products.

Without an $\mathrm{OH}$ scavenger, $\mathrm{OH}$ generated during photolysis might react with $\mathrm{C}_{6}$-HPALD, leading to an observed product distribution that includes both photolysis and $\mathrm{OH}$-reaction products; however, several lines of evidence suggest this is not the case. First, the loss rate of $\mathrm{C}_{6}$-HPALD in this experiment is comparable to that in the $\mathrm{OH}$ scavenging experiments (Table 1), implying that reaction with $\mathrm{OH}$ is not a major sink for $\mathrm{C}_{6}$-HPALD. Secondly, none of the major products observed in the $\mathrm{OH}$ reaction experiments (see below) were observed in the

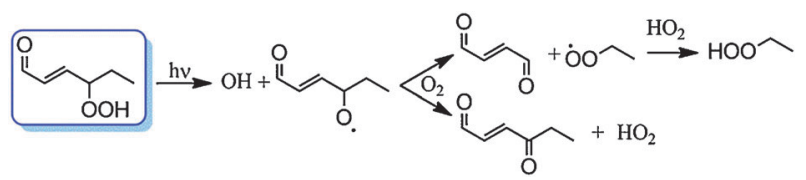

Scheme 1 Predicted mechanism for $\mathrm{C}_{6}$-HPALD photolysis and subsequent degradation under low-NO conditions. The alkoxy radical should rapidly decompose in the presence of $\mathrm{O}_{2}$ to make either fumaraldehyde and ethyl peroxy radical (upper channel) or a $\mathrm{C}_{6}$ dicarbonyl and $\mathrm{HO}_{2}$ (lower channel). photolysis experiment, though this may be attributed to drastically different $\mathrm{NO}_{x}$ concentrations between these two experiments. The fate of $\mathrm{OH}$ in this experiment remains unclear, but the fact that the $\mathrm{C}_{6}$-HPALD loss rate is not noticeably faster when compared to experiments that include an $\mathrm{OH}$ scavenger suggests the presence of unidentified $\mathrm{OH}$ sinks. The magnitude of this sink would need to be reasonably large to compete with $\mathrm{C}_{6}$-HPALD $\left(\mathrm{k}_{\mathrm{OH}+\mathrm{HPALD}}[\mathrm{HPALD}]=40 \mathrm{~s}^{-1}\right.$ at start of experiment) and would need to be even larger to compete with phenol in the $\mathrm{OH}$ scavenging experiments $\left(\mathrm{k}_{\mathrm{OH}}+\right.$ Phenol[Phenol] $=$ 360 to $2700 \mathrm{~s}^{-1}$ ). Still, the $\mathrm{OH}$ yield derived above should be considered a lower limit.

\subsection{OH reaction rate}

To determine the rate constant for reaction of $\mathrm{C}_{6}$-HPALD with $\mathrm{OH}$, relative rates experiments were conducted using DHB and MACR as reference compounds. These compounds were chosen because their $\mathrm{OH}$ reaction rate constants $(1.0 \times$ $10^{-10}$ and $2.9 \times 10^{-11} \mathrm{~cm}^{3}$ molecule ${ }^{-1} \mathrm{~s}^{-1}$ at $298 \mathrm{~K}$, respectively $)^{36}$ bracket the value of $5.2 \times 10^{-11} \mathrm{~cm}^{3}$ molecule ${ }^{-1} \mathrm{~s}^{-1}$ estimated by Peeters and Müller ${ }^{16}$ for $\mathrm{C}_{5}$-HPALDs using structure reactivity relationships. Photolysis of $\mathrm{CH}_{3} \mathrm{ONO}$ under "low" illumination provided the $\mathrm{OH}$ source. A photochemical box model calculation suggests $\mathrm{OH}$ concentrations of 4-6 $\times 10^{5}$ molecules $\mathrm{cm}^{-3}$ for the first three hours, consistent with the observed reference compound decays. Based on the measured photon flux and our earlier results, the $\mathrm{C}_{6}$-HPALD photolysis rate constant for these experiments is estimated at $0.2 \times 10^{-5} \mathrm{~s}^{-1}$, which is less than $8 \%$ of the observed $\mathrm{C}_{6}$-HPALD decay. $\mathrm{C}_{6}$-HPALD profiles were corrected for this first-order loss following eqn (1) before calculation of the $\mathrm{OH}$ reaction rate constant using the standard formula ${ }^{37}$

$$
\frac{\ln \left(\mathrm{HPALD}_{\mathrm{O}} / \mathrm{HPALD}\right)}{\ln \left(\mathrm{X}_{\mathrm{O}} / \mathrm{X}\right)}=\frac{\mathrm{k}_{\mathrm{HPALD}+\mathrm{OH}}}{\mathrm{k}_{\mathrm{X}+\mathrm{OH}}}
$$

Here, the left-hand side is given by the slope of a plot of the normalized logarithmic decays for $\mathrm{C}_{6}$-HPALD versus the reference compound $\mathrm{X}$ (Fig. 3). From two such experiments (Table 2), the mean rate constant is $(5.1 \pm 1.8) \times 10^{-11} \mathrm{~cm}^{3}$ molecule ${ }^{-1} \mathrm{~s}^{-1}$. On average, the rate constant derived from

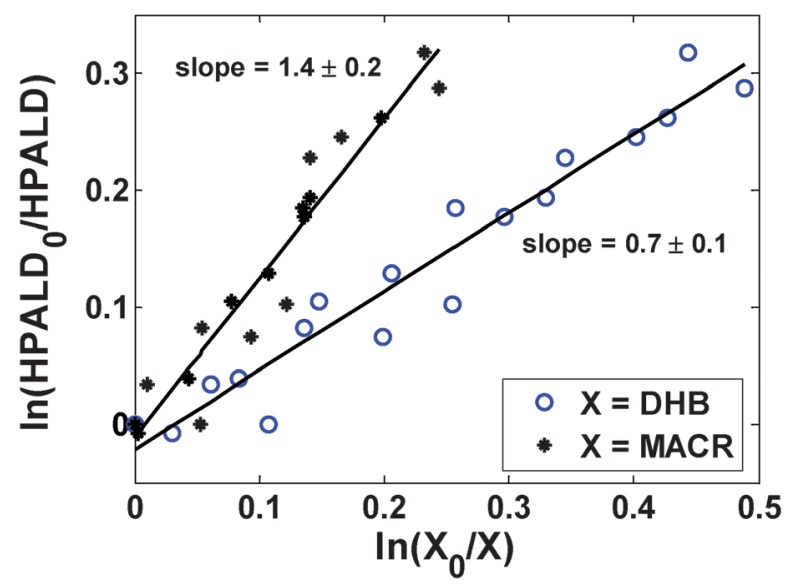

Fig. 3 Correlations of $\mathrm{OH}$-initiated decays of $\mathrm{C}_{6}$-HPALD and reference compounds $(\mathrm{X}=\mathrm{DHB}$ and $\mathrm{MACR})$ for the first $3 \mathrm{~h}$ of experiment $\mathrm{OH} 1$. 
Table 2 Summary of $\mathrm{OH}$ reaction experiments

\begin{tabular}{lllllllll}
\hline Exp. & $\begin{array}{l}{[\mathrm{HPALD}]_{0}} \\
(\mathrm{ppbv})\end{array}$ & $\begin{array}{l}{[\mathrm{DHB}]_{0}} \\
(\mathrm{ppbv})\end{array}$ & $\begin{array}{l}{[\mathrm{MACR}]_{0}} \\
(\mathrm{ppbv})\end{array}$ & $\begin{array}{l}{\left[\mathrm{CH} \mathrm{ONO}_{0} \mathrm{ONO}\right.} \\
(\mathrm{ppbv})\end{array}$ & $\begin{array}{l}\text { Slope } v s . \\
\mathrm{DHB}\end{array}$ & $\begin{array}{l}\text { Slope } v s . \\
\text { MACR }\end{array}$ & $\begin{array}{l}\mathrm{k}_{\mathrm{OH}} v s . \mathrm{DHB} \\
\left(10^{-11} \mathrm{~cm}^{3} \mathrm{molec}^{-1} \mathrm{~s}^{-1}\right)\end{array}$ & $\begin{array}{l}\mathrm{k}_{\mathrm{OH}} v s . \mathrm{MACR} \\
\left(10^{-11} \mathrm{~cm}^{3} \mathrm{molec}^{-1} \mathrm{~s}^{-1}\right)\end{array}$ \\
\hline OH1 & 2.69 & 27.3 & 14.7 & 183 & $0.72 \pm 0.09$ & $1.4 \pm 0.2$ & $7.2 \pm 0.9$ & $4.1 \pm 0.6$ \\
OH2 & 3.89 & 4.6 & 10.7 & 184 & $0.59 \pm 0.07$ & $1.1 \pm 0.2$ & $5.9 \pm 0.7$ & $3.2 \pm 0.6$ \\
Avg & & & & & & - & $\mathbf{5 . 1} \pm \mathbf{1 . 8}$ & - \\
OH3 & 46.7 & 0 & 0 & 490 & - & - & -
\end{tabular}

Slopes are calculated from linear least-squares fits to scatter plots of logarithmic decays of $\mathrm{C}_{6}$-HPALD and the reference compound (DHB or MACR) from the first $3 \mathrm{~h}$ of each experiment. Errors represent the $2 \sigma$ uncertainty in the fits. The average and its uncertainty are calculated from the mean and standard deviation of the four values. The last experiment was performed without reference compounds to examine the product distribution.

MACR is $\sim 40 \%$ lower than that derived from DHB. The reason for this discrepancy is not clear, thus we include results from both reference compounds in our average and use the standard deviation of these values to define the uncertainty.

\subsection{OH reaction products}

$\mathrm{C}_{6}$-HPALD possesses a number of potential reaction sites; likely reaction pathways are summarized in Scheme 2. These include abstraction of the aldehydic hydrogen $\left(\mathrm{C}_{1}\right)$, addition of $\mathrm{OH}$ to either side of the double-bond $\left(\mathrm{C}_{2}\right.$ and $\left.\mathrm{C}_{3}\right)$, and abstraction of the $\delta-\mathrm{H}$ adjacent to the peroxide group $\left(\mathrm{C}_{4}\right)$. Abstractions of hydrogen from the peroxide or ethyl groups are likely minor channels (not shown). Given the similarity between $\mathrm{C}_{6}$-HPALD and the isoprene-derived $\mathrm{C}_{5}$-HPALDs, we can expect the $\mathrm{OH}$ reaction branching for these molecules to be loosely similar, but with some key differences (discussed below). VOC products observed during $\mathrm{OH}$ oxidation (experiment $\mathrm{OH} 3$ in Table 2) can provide some information on the branching of the $\mathrm{C}_{6}$-HPALD $+\mathrm{OH}$ reaction.

Owing to high levels of $\mathrm{NO}_{x}(\sim 250$ pptv NO and $0-40$ ppbv $\mathrm{NO}_{2}$ ) from the $\mathrm{OH}$ source, multifunctional organic nitrates are expected as products. The most abundant of these, the $\mathrm{C}_{6}$-HPALD acyl peroxy nitrate (APN), was identified from its mass (negative $m / z 292$ ) and the appearance of $m / z 62$ in the tandem mass spectrum, a fingerprint for APNs corresponding to $\mathrm{NO}_{3}{ }^{-}$. Using the same calibration factor as that applied to $\mathrm{C}_{6}$-HPALD, the APN yield is estimated to be $27 \%$ over the first $1.5 \mathrm{~h}$ of oxidation (Fig. 4a). At longer times, APN $+\mathrm{OH}$ reactions compete with, and eventually outrun, APN production. Thermal decomposition does not influence APN concentrations here, as the high $\mathrm{NO}_{2}$ concentrations force all acyl peroxy radicals into the APN reservoir. Therefore, the APN yield gives a direct estimate for the branching of $\mathrm{OH}$ reaction via abstraction of the aldehydic hydrogen (pathway $\mathrm{C}_{1}$ in Scheme 2).

The second largest product signal appears at negative $\mathrm{m} / \mathrm{z}$ 65 , corresponding to the fluoride transfer mass of formic acid. Using the sensitivity estimated from ion-molecule collision rates $^{38}$ gives a formic acid yield of $24 \%$ (Fig. 4a). The source of formic acid is not clear, though it is possible that this compound is produced through unidentified isomerization pathways after $\mathrm{OH}$ addition enables rotation about the $\mathrm{C}_{2}-\mathrm{C}_{3}$ bond.

The fraction of the reactive flux proceeding through predicted isomerization pathways $\left(\mathrm{C}_{2}\right.$ and $\mathrm{C}_{3}$ in Scheme 2) depends on the NO concentration and the rates of the competing 1,4- 1,5- and 1,6-H-shift isomerization channels.
Crounse et al. ${ }^{39}$ report the 1,4-H-shift of the aldehydic hydrogen in the dominant $\mathrm{RO}_{2}$ in methacrolein oxidation to be quite fast $\left(\sim 0.5 \mathrm{~s}^{-1}\right.$ at $\left.T=296 \mathrm{~K}\right)$. Under low-NO conditions such as those observed in the Amazon $(<20$ pptv $){ }^{6}$ such unimolecular chemistry may dominate the lifetime of certain $\mathrm{RO}_{2}$. Photochemical modeling suggests an NO mixing ratio of $\sim 250$ pptv during this experiment, giving a peroxy radical lifetime of $\sim 18 \mathrm{~s}$ with respect to NO using the MCMrecommended generic $\mathrm{RO}_{2}+\mathrm{NO}$ rate constant. ${ }^{40}$ Rates of isomerization cannot be estimated from the available data, but the CIMS should be sensitive to the products of these reactions. Expected signals at $m / z-219, m / z-235$ and $m / z-247$ for clusters with the isomerization products of $3-\mathrm{OH}$ and 2-OH addition were not observed (shaded molecules in Scheme 2), though the appreciable molar mass and high $\mathrm{O}: \mathrm{C}$ ratios ( 0.8 to 1$)$ of these compounds implies that such compounds may readily partition to chamber walls. Moreover, the growth of signals at the expected $\mathrm{CF}_{3} \mathrm{O}^{-}$cluster or $\mathrm{H}^{+}$transfer masses for propanal $(m / z+59)$, 2-hydroperoxybutanal $(m / z-189)$ and 2-hydroxydipropanal $(m / z-173$ and $m / z+89)$ are qualitatively consistent with the expected products of $\mathrm{RO}_{2}+\mathrm{NO}$ reactions (green, black and magenta symbols/boxes Scheme 2 and Fig. 4b). It is also possible that the $\alpha$-hydroperoxyalkyl radical resulting from $\mathrm{C}_{2} \mathrm{OH}$ addition could lead to formation of an epoxide ${ }^{19}$ that would be detected at negative $m / z$ 215. Tandem MS/MS at this mass shows no evidence for such a compound, though we might expect that such a molecule would readily partition to chamber walls and not build up to an observable concentration. Unfortunately, the data does not permit a conclusive statement on the branching of the remaining $\mathrm{OH}$ reaction channels.

\section{$3.5 \mathrm{O}_{3}$ reaction rate}

The reaction rates of $\mathrm{O}_{3}$ with $\mathrm{C}_{6^{-}}$and $\mathrm{C}_{5}$-HPALDs were determined from their first order decay rates over a 2-hour reaction period (data available in ESI). $\dagger$ During these experiments, $\mathrm{O}_{3}$ concentrations decayed from their initial level by $\sim 20 \%$. For determination of rate constants, we use the average $\mathrm{O}_{3}$ concentration over this interval. Wall-loss corrections were made for both the $\mathrm{C}_{6}$-HPALD and $\mathrm{C}_{5}$-HPALDs prior to determining the first-order loss rate. We find the reaction rate of $\mathrm{O}_{3}$ with $\mathrm{C}_{6}$-HPALD at $296 \mathrm{~K}$ to be $(1.2 \pm 0.2) \times$ $10^{-18} \mathrm{~cm}^{3}$ molecule $\mathrm{s}^{-1}$ from the average of two experiments, and the reaction rate of $\mathrm{O}_{3}$ with $\mathrm{C}_{5}$-HPALDs to be $1.1 \times$ $10^{-18} \mathrm{~cm}^{3}$ molecule $\mathrm{s}^{-1} \mathrm{~s}^{-1}$ from a single experiment (Table 3 ). 


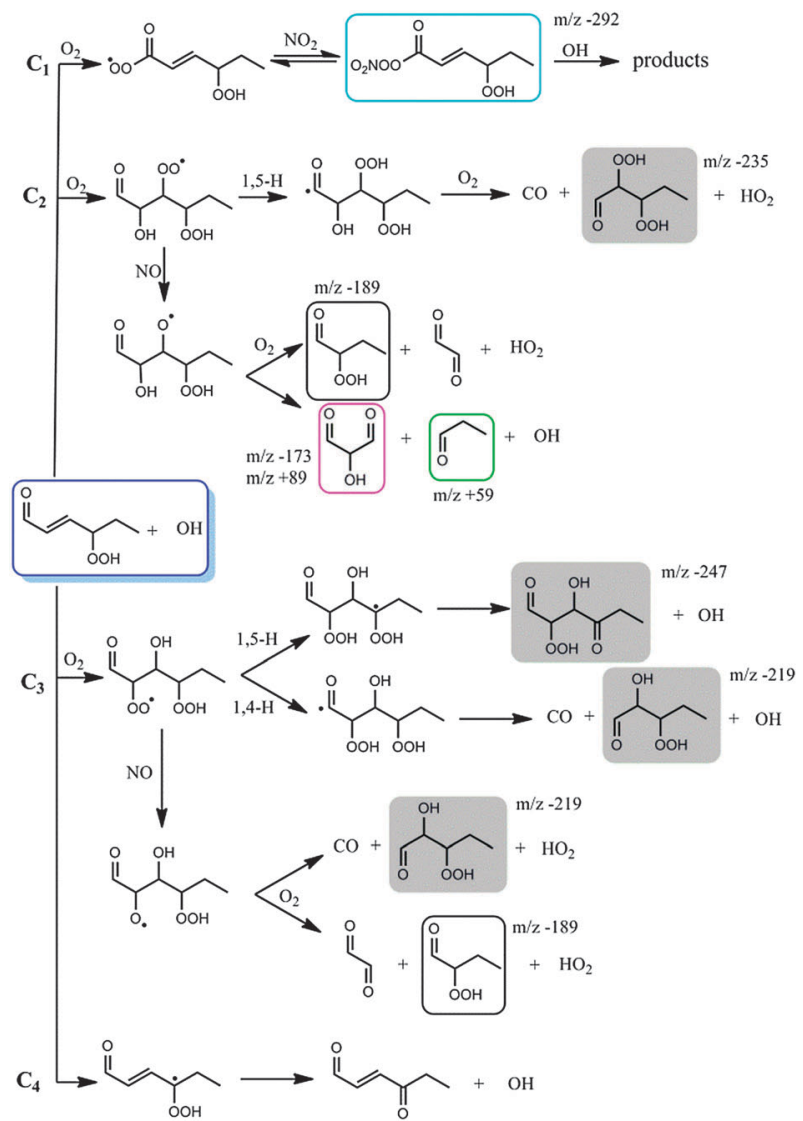

Scheme 2 Predicted mechanism for $\mathrm{C}_{6}$-HPALD reaction with $\mathrm{OH}$ and subsequent degradation under high- $\mathrm{NO}_{x}$ conditions. Colored boxes correspond to product profiles shown in Fig. 4. Shaded boxes correspond to products that were not observed. Expected $m / z$ signals in the CIMS spectra are also given.

For an atmospheric $\mathrm{O}_{3}$ concentration of 40 ppbv, boundary layer $\mathrm{O}_{3}$ lifetimes for isoprene-derived $\mathrm{C}_{5}$-HPALDs are calculated to be approximately 10 days. Given the fast photolysis and $\mathrm{OH}$ reaction rates, it is clear that $\mathrm{C}_{5}$-HPALD reaction with $\mathrm{O}_{3}$ will not be an important loss process in the atmosphere.

\subsection{Comparison between $\mathrm{C}_{6}$-HPALD and $\mathrm{C}_{5}$-HPALDs}

Overall, our results for the $\mathrm{C}_{6}$-HPALD agree with firstprinciples estimates for the fate of isoprene-derived $\mathrm{C}_{5}$-HPALDs. ${ }^{16}$ The measured photolysis quantum yield of $1.0 \pm 0.4$ implies very efficient photolysis, as predicted. This number is directly dependent on the assumed absorption cross-section, and more work is needed to quantify the latter parameter directly. The high $\mathrm{OH}$ yield of $1.0 \pm 0.8$ is consistent with the expected photolysis mechanism, though the uncertainty in this value precludes a definitive conclusion. It seems unlikely that the $\mathrm{OH}$ yield is much less than unity, given the low quantum yield $(<0.05)$ for molecules featuring the same $\mathrm{O}=\mathrm{C}-\mathrm{C}=\mathrm{C}$ chromophore but without the peroxide functionality (e.g., MVK, MACR, acrolein and trans-2hexenal). ${ }^{41}$ A quantum yield greater than 1 could indicate secondary $\mathrm{OH}$ production from decomposition of the alkoxy co-product. Though we expect the initial photolysis step to be the same for both $\mathrm{C}_{5^{-}}$and $\mathrm{C}_{6}$-HPALDs, the subsequent
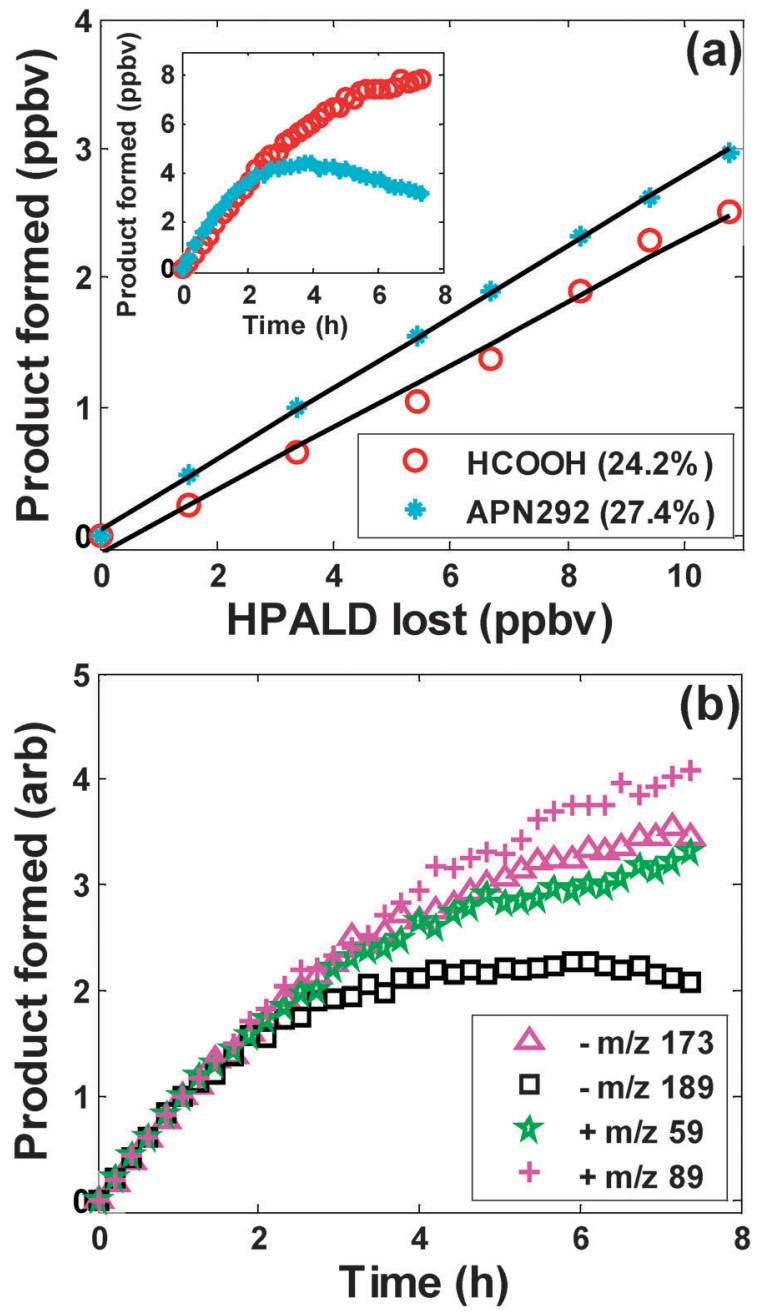

Fig. 4 (a) Formation of formic acid and the $\mathrm{C}_{6}$-HPALD acyl peroxy nitrate (APN292) over the first $1.5 \mathrm{~h}$ of the $\mathrm{OH}$ oxidation experiment $\mathrm{OH} 3$. The inset shows the time-evolution of these species over the entire experiment. (b) Growth of product ions observed during the same experiment. Signals are arbitrarily normalized to appear on the same scale. Colors correspond to predicted products as highlighted in Scheme 2: propanal $(m / z+59)$, 2-hydroperoxybutanal $(m / z-189)$, and 2-hydroxydipropanal $(m / z-173$ and $m / z+89)$.

Table 3 Summary of $\mathrm{O}_{3}$ reaction experiments

\begin{tabular}{llllll}
\hline & $\begin{array}{l}\text { [HPALD }]_{0} \\
\text { (ppbv) }\end{array}$ & $\begin{array}{l}{\left[\mathrm{O}_{3}\right]_{\text {avg }}} \\
\text { (ppbv) }\end{array}$ & $\begin{array}{l}{[\mathrm{Phenol}]_{0}} \\
(\mathrm{ppbv})\end{array}$ & $\begin{array}{l}\mathrm{Slope} \\
\left(10^{-5} \mathrm{~s}^{-1}\right)\end{array}$ & $\begin{array}{l}\mathrm{k}_{\mathrm{O} 3} \\
\left(10^{-18} \mathrm{~cm}^{3}\right. \\
\left.\mathrm{molec}^{-1} \mathrm{~s}^{-1}\right)\end{array}$ \\
\hline OZ1 & 5.10 & 348 & 2200 & $1.16 \pm 0.05$ & $1.4 \pm 0.2$ \\
OZ2 & 4.16 & 830 & 1750 & $2.12 \pm 0.07$ & $1.1 \pm 0.2$ \\
Avg & & & & & $\mathbf{1 . 2} \pm \mathbf{0 . 2}$ \\
OZ3 & 2.49 & 2495 & 1340 & $6.7 \pm 0.1$ & $1.1 \pm 0.2$
\end{tabular}

Slopes are calculated from linear least-squares fits to scatter plots of logarithmic decays of HPALD for the first $2 \mathrm{~h}$ of each experiment. Errors in the slopes represent the $1 \sigma$ uncertainty in the fits. Ozone concentrations are given as the average over the 2-hour experiment. Errors in the rates constants include contributions from wall loss corrections for HPALDs and a $10 \%$ uncertainty from using the average $\mathrm{O}_{3}$ concentration. The average rate constant is uncertaintyweighted $\left(1 / \sigma^{2}\right)$. Experiments OZ1 and OZ2 used $\mathrm{C}_{6}$-HPALD, while experiment $\mathrm{OZ} 3$ was performed with photochemically-generated $\mathrm{C}_{5}$-HPALDs. 
chemistry is necessarily different. In particular, the $(E)$ configuration of the $\mathrm{C}_{6}$-HPALD prevents the unimolecular hydrogen shifts that, in the case of the $(Z)-C_{5}$-HPALD photolysis co-products, are predicted to lead to formation of peroxy-acid-enals (PACALDs). ${ }^{16}$ The latter are predicted to also photolyze rapidly to yield additional $\mathrm{OH}$ radicals; however, unlike the $\mathrm{C}_{5}$-HPALDs, they have yet to be observed.

The measured $\mathrm{OH}$ reaction rate constant of $(5.1 \pm 1.8) \times$ $10^{-11} \mathrm{~cm}^{3}$ molecule ${ }^{-1} \mathrm{~s}^{-1}$ is also very close to the value of $5.2 \times 10^{-11} \mathrm{~cm}^{3}$ molecule ${ }^{-1} \mathrm{~s}^{-1}$ estimated from structurereactivity relationships for the $\mathrm{C}_{5}$-HPALDs. ${ }^{16}$ Combining the $\mathrm{C}_{6}$-HPALD APN yield of 0.27 with this value gives an estimated rate constant of $1.3 \times 10^{-11} \mathrm{~cm}^{3}$ molecule $^{-1} \mathrm{~s}^{-1}$ for abstraction of the aldehydic $\mathrm{H}$, in fair agreement with the value of $1.5 \times 10^{-11} \mathrm{~cm}^{3}$ molecule ${ }^{-1} \mathrm{~s}^{-1}$ for $\mathrm{CH}_{3} \mathrm{CHO}^{36}$ Note that the products for this channel may be different for the $\mathrm{C}_{5}$-HPALDs; in particular, fast $1,6-\mathrm{H}$ shifts may prevent formation of a $\mathrm{C}_{5}$-HPALD APN under atmosphericallyrelevant $\mathrm{NO}_{2}$ concentrations. We cannot make a quantitative comparison for the other $\mathrm{OH}$ reaction channels at this time. It is expected that $\mathrm{OH}$ addition should be somewhat slower for the $\mathrm{C}_{6}$-HPALD since addition to either site would result in a secondary alkyl radical (as opposed to a secondary and a tertiary radical), ${ }^{42}$ while $\mathrm{H}$-abstraction from the $\mathrm{C}_{4}$-carbon should be roughly 2 to 3 times faster for $\mathrm{C}_{6}$-HPALD compared to $\mathrm{C}_{5}$-HPALD because of the secondary carbon. ${ }^{43}$

It is not possible to assess the degree of $\mathrm{HO}_{\mathrm{x}}$ recycling from reactions of $\mathrm{OH}$ with $\mathrm{C}_{6}$-HPALD from the available data. As with the $\mathrm{C}_{5}$-HPALDs, ${ }^{16,17}$ our proposed mechanism (Scheme 2) indicates that these reactions should be effectively $\mathrm{HO}_{\mathrm{x}}$-neutral. Future experiments could shed light on this component of the mechanism.

\section{Atmospheric implications}

The impact of $\mathrm{C}_{5}$-HPALDs on atmospheric oxidation ultimately depends on both their production rate and their subsequent photochemistry. Global models ${ }^{20,22}$ have demonstrated dramatic increases in $\mathrm{OH}$-by factors of 3 or more in some regions-upon incorporating the $\mathrm{ISO}_{2}$ isomerization and $\mathrm{C}_{5}$-HPALD chemistry as originally proposed. ${ }^{21,22}$ This mechanism also affects the distribution of oxidized VOC, leading Archibald et al. ${ }^{22}$ to suggest that calculated isomerization rates should be reduced by an order of magnitude. In a recent experimental study, Crounse et al. ${ }^{18}$ observed a $\mathrm{C}_{5}$-HPALD production rate that is 25 to 75 times slower than the original quantum mechanical prediction. ${ }^{16}$

A simple 0-D box model calculation can illustrate the impact of the revised isomerization/HPALD mechanism on $\mathrm{OH}$ as a function of isoprene and NO concentrations. Calculations were performed using a modified version of the UW-CAFE model ${ }^{10}$ updated with Master Chemical Mechanism (MCM) v3.2 chemistry. ${ }^{40,44}$ The model was initialized with fixed meteorology $(T=298 \mathrm{~K}, \mathrm{P}=760$ Torr, $\mathrm{RH}=30 \%$, SZA $=7^{\circ}$ ) and a "dilution rate" of $0.3 \mathrm{~h}^{-1}$ with background concentrations of 0 for all secondary species. Initial chemical concentrations, held fixed throughout each model run, were 50 ppbv $\mathrm{O}_{3}, 100 \mathrm{ppbv} \mathrm{CO}, 0-1 \mathrm{ppbv} \mathrm{NO}$ and $0-5 \mathrm{ppbv}$ isoprene. Model integration time of $3 \mathrm{~h}$ was sufficient for
$\mathrm{OH}$ to reach steady state. Simulations included two scenarios: a base case using default MCM $v 3.2$ chemistry, and a test case using the experimentally-constrained isomerization/HPALD chemistry. The latter includes the $\mathrm{C}_{5}$-HPALD formation rate recommended by Crounse et al. ${ }^{18}$ the $1,5-\mathrm{H}$ isomerization rate calculated by da Silva et al. ${ }^{14}$ (consistent with auxiliary results in Crounse et al. ${ }^{18}$ ), a $\mathrm{C}_{5}$-HPALD photolysis quantum yield of 1 (implemented by scaling the MACR photolysis rate), and a conservative $\mathrm{C}_{5}$-HPALD photolysis $\mathrm{OH}$ yield of 1 . Reactions of $\mathrm{C}_{5}$-HPALD with $\mathrm{OH}$ were given a rate constant of $5.1 \times$ $10^{-11} \mathrm{~cm}^{3}$ molecule ${ }^{-1} \mathrm{~s}^{-1}$ and were assumed to consume $\mathrm{C}_{5}$-HPALD but not $\mathrm{OH}$, implying $100 \% \mathrm{OH}$ recycling through this pathway. This mechanism is conservative by design; thus, we do not included oxidized VOC from $\mathrm{C}_{5}$-HPALD photolysis and $\mathrm{OH}$ reaction (e.g., PACALDs), as the nature of these products is still uncertain. This carries consequences for the impact on $\mathrm{OH}$, as discussed further below.

As expected, the fractional increase in modeled $\mathrm{OH}$ is greatest at low $\mathrm{NO}$ and high isoprene, where $\mathrm{ISO}_{2}$ concentrations are relatively high and the lifetime of $\mathrm{ISO}_{2}$ is relatively long (Fig. 5). A sensitivity test shows that about one third of this increase is due to the "prompt" effects of isomerization (reduced peroxide formation and increased $\mathrm{HO}_{2}$ production), while the remaining two thirds results from $\mathrm{C}_{5}$-HPALD photolysis. Within the range of observations (white circles in Fig. 5), modeled $\mathrm{OH}$ is enhanced by $5-16 \%$ relative to the standard isoprene mechanism. Most recent observational studies in rural and remote biogenically-influenced terrestrial regions require a factor of 2 to 10 increase in $\mathrm{OH}$ to reconcile models and measurements (Table 4).

Assumptions regarding the rate of $\mathrm{ISO}_{2}$ isomerization and the fate of $\mathrm{C}_{5}$-HPALD oxidation products have a direct impact on the modeled $\mathrm{OH}$ enhancement. Thus, we have performed several additional model runs, the detailed results of which are available in the ESI $\dagger$ and summarized here. First, increasing the 1,6- and 1,5- $\mathrm{H}$ shift isomerization rates to their theoretical predictions ${ }^{16,17}$ increases the above-quoted range of $\mathrm{OH}$ enhancement to $40-210 \%$. This change also causes the $\mathrm{OH}$ enhancement to exhibit a non-monotonic dependence on NO for higher isoprene mixing ratios, reflecting the impact of additional $\mathrm{HO}_{2}$ radicals from isomerization. Next, we revert to the experimentally-constrained isomerization rates but expand the $\mathrm{C}_{5}$-HPALD mechanism to include 1) production of $\mathrm{HO}_{2}$ and PACALDs from photolysis, and 2) photolysis of PACALDs to make $2 \mathrm{OH}$ radicals, with a rate constant equal to twice that of the $\mathrm{C}_{5}$-HPALDs. ${ }^{16}$ The resulting $\mathrm{OH}$ enhancement over the range of observations is $9-35 \%$. Together, the above two results suggest that isomerization is the limiting step in our experimentally-constrained mechanism. Using both the theoretical isomerization rates and extended $\mathrm{C}_{5}$-HPALD chemistry yields much larger $\mathrm{OH}$ enhancements, in the range of $200-475 \%$. The full theoretical mechanism has been shown to dramatically reduce model-measurement discrepancies in $\mathrm{OH}$ concentrations for at least one case. ${ }^{21}$ On the other hand, recent work has also called into question the accuracy of $\mathrm{OH}$ concentrations observed via laser-induced fluorescence in biogenic-dominated regions. ${ }^{48}$

As noted and accounted for in earlier theoretical work ${ }^{16,20}$ and recently highlighted, ${ }^{21}$ the influence of $\mathrm{C}_{5}$-HPALD 


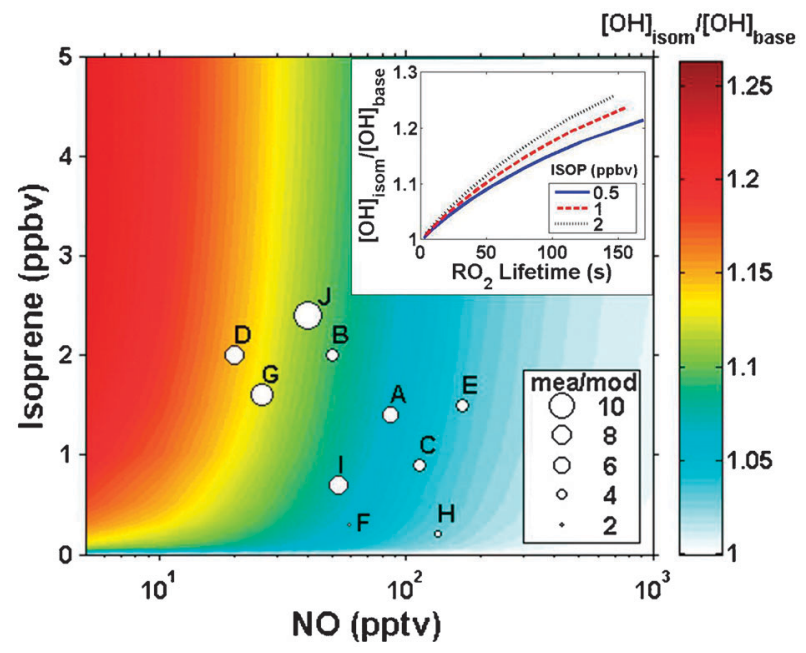

Fig. 5 Simulated fractional change in $\mathrm{OH}$ concentrations resulting from the isomerization of isoprene peroxy radicals and the subsequent photolysis and $\mathrm{OH}$ oxidation of $\mathrm{C}_{5}$-HPALDs. 0-D box model calculations use the observed rate of $\mathrm{C}_{5}$-HPALD production from $\mathrm{ISO}_{2}$ isomerization $^{18}$ and a photolysis $\mathrm{OH}$ yield of 1 . Circles and corresponding letters denote chemical regimes for observational studies (Table 4). Circle sizes correspond to the ratio of measured to modelled $\mathrm{OH}$. The inset shows the fractional increase in $\mathrm{OH}$ concentrations as a function of total $\mathrm{RO}_{2}$ lifetime at three different isoprene concentrations. Increasing $\mathrm{RO}_{2}$ lifetimes scale with decreasing $\mathrm{NO}$ concentrations.

Table 4 Summary of $\mathrm{OH}$ model-measurement comparisons in rural and remote regions

\begin{tabular}{|c|c|c|c|c|}
\hline Campaign & $\begin{array}{l}\text { Isoprene } \\
\text { (ppbv) }\end{array}$ & $\begin{array}{l}\text { NO } \\
\text { (pptv) }\end{array}$ & $\begin{array}{l}\text { OH mea/ } \\
\text { mod }\end{array}$ & Symbol \\
\hline AEROBIC $1997^{45}$ & $1.4^{*}$ & $86^{*}$ & $3^{\#}$ & A \\
\hline PROPHET $1998^{8}$ & $2 *$ & $50^{*}$ & $2.66^{@}$ & $\mathrm{~B}$ \\
\hline INTEX-A $2004^{7,20}$ & $0.9^{\wedge}$ & $114^{\wedge}$ & $2.5^{\#}$ & $\mathrm{C}$ \\
\hline GABRIEL $2005^{6,20}$ & $2.0 \pm 0.8^{\wedge}$ & $20 \pm 20^{\wedge}$ & $5.3^{@}$ & $\mathrm{D}$ \\
\hline PRiDe $2006^{5}$ & $1.5^{*}$ & $170^{*}$ & $2.6^{\#}$ & $\mathrm{E}$ \\
\hline AMMA $2006^{46,47}$ & $0.3 \pm 0.3^{\wedge}$ & $59 \pm 30^{\wedge}$ & $0.40^{@}$ & $\mathrm{~F}$ \\
\hline BEARPEX 2007 (hot) ${ }^{10}$ & $1.6 \pm 0.7 *$ & $26 \pm 12 *$ & $6^{\#}$ & G \\
\hline BEARPEX $2007(\mathrm{cool})^{10}$ & $0.2 \pm 0.1^{*}$ & $135 \pm 42 *$ & $0.95^{\#}$ & $\mathrm{H}$ \\
\hline OP3 2008 (flight) $^{11}$ & $0.7 \pm 1.6^{\wedge}$ & $53 \pm 109^{\wedge}$ & $4.5^{@}$ & I \\
\hline OP3 2008 (ground) $^{12}$ & $2.4 \pm 1.0^{*}$ & $40 \pm 10^{*}$ & $10^{\#}$ & $\mathrm{~J}$ \\
\hline
\end{tabular}

Isoprene and NO mixing ratios are midday averages $(*)$ or campaign averages in "high isoprene" regions such as the forested boundary layer $\left(^{\wedge}\right)$. NO mixing ratios for BEARPEX-2007 are calculated from a 1-D canopy model constrained by $\mathrm{NO}_{2}$ observations. Standard deviations are provided when available. Ratios of measured/modelled $\mathrm{OH}$ are from either single averaged points (\#) or a scatter plot of all data (@). The "symbol" corresponds to the location of the data point in Fig. 5 and 6.

chemistry on the radical budget depends on the relative rates of $\mathrm{C}_{5}$-HPALD photolysis (which generates $\mathrm{OH}$ ) and $\mathrm{OH}$ reaction (which removes $\mathrm{C}_{5}$-HPALDs and, possibly, also $\mathrm{OH}$ ). Fig. 6 illustrates this competition over a range of photolysis rates and $\mathrm{OH}$ concentrations. $\mathrm{C}_{5}$-HPALD photolysis rates were derived as a function of solar zenith angle by scaling the MCM v3.2 parameterization $^{40,44}$ for MACR photolysis to a quantum yield of 1 . In this case, the maximum $\mathrm{C}_{5}$-HPALD photolysis rate is $4.3 \times 10^{-4} \mathrm{~s}^{-1}$ for an overhead sun. Even at fairly high $\mathrm{OH}\left(\sim 10^{7}\right.$ molec $\left.\mathrm{cm}^{-3}\right)$, photolysis comprises

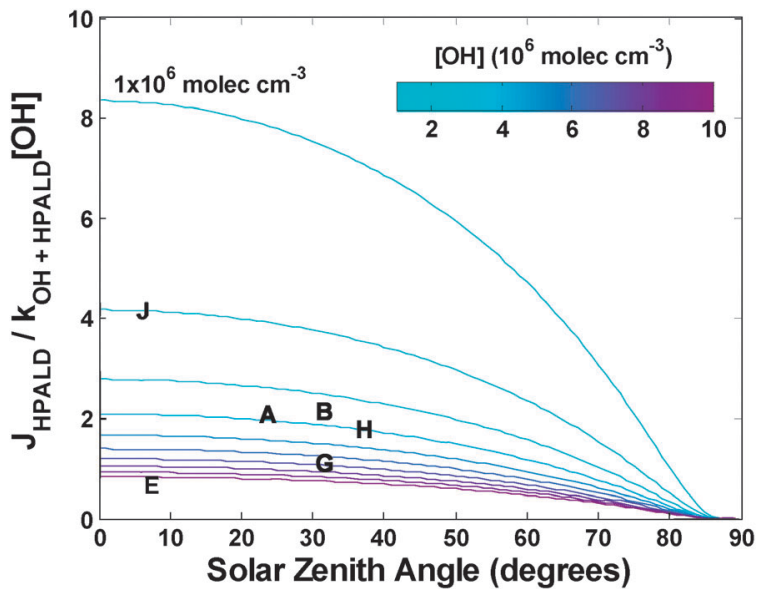

Fig. 6 Ratio of $\mathrm{C}_{5}$-HPALD photolysis and $\mathrm{OH}$ reaction rates as a function of solar zenith angle and $\mathrm{OH}$ concentration. Lines represent $\mathrm{OH}$ isopleths spaced by $1 \times 10^{6} \mathrm{molec} \mathrm{cm}^{-3}$. Letters indicate approximate midday conditions for several of the observations listed in Table 4.

$\sim 40 \%$ of the $\mathrm{C}_{5}$-HPALD sink for typical tropical and mid-latitude midday sunlight conditions. A number of $\mathrm{OH}$ observational studies have occurred in regions where the rate of photolysis exceeds that of $\mathrm{OH}$ oxidation, thus we do expect inclusion of $\mathrm{C}_{5}$-HPALD chemistry to reduce model-measurement discrepancies.

We further evaluate the impact of $\mathrm{C}_{5}$-HPALD photochemistry using the GEOS-Chem chemical transport model ${ }^{49}$ v8.2.1. The model is driven by the GEOS-5 assimilated meteorology from the NASA Goddard Earth Observing System. Here the resolution of the model is $4 \times 5$ with 47 vertical layers. We use the simplified isoprene photochemical mechanism presented by Paulot et al. ${ }^{50}$ In the sensitivity simulation, HPALD formation is included using the experimental reaction rate derived by Crounse et al., ${ }^{18}$ and we include $\mathrm{C}_{5}$-HPALD photolysis and reaction with $\mathrm{OH}$ as described in this study. $\mathrm{C}_{5}$-HPALD photolysis is assumed to yield one $\mathrm{OH}$ and one $\mathrm{HO}_{2}$ while the reaction with $\mathrm{OH}$ is assumed to be $\mathrm{OH}$ neutral. Deposition and transport of $\mathrm{C}_{5}$-HPALD are not treated. Consistent with the results of UW-CAFE model, we find that boundary layer $\mathrm{OH}$ increases by up to $20 \%$ under very high isoprene/NO ratios (Fig. 7). The geographical distribution of modeled $\mathrm{OH}$ enhancement differs from that of the fraction of $\mathrm{ISO}_{2}$ that isomerizes (compare with Fig. 3 of Crounse et ll. $^{39}$ ), as the former depends also on isoprene emission rates, $\mathrm{C}_{5}$-HPALD photolysis rates and $\mathrm{OH}$ concentrations.

Irrespective of the current debate surrounding isomerization rates, this new chemistry is clearly significant and should be included in isoprene oxidation mechanisms. Future studies should particularly focus on quantifying the nature and fate of HPALD oxidation products (e.g., $\mathrm{HO}_{2}$ and PACALDs), as these may also impact $\mathrm{HO}_{\mathrm{x}}$ budgets. Moreover, isomerization mechanisms such as those discussed in this work inherently increase the $\mathrm{O}: \mathrm{C}$ ratio while retaining the carbon backbone; thus, we expect $\mathrm{C}_{5}$-HPALDs and their oxidation products to exhibit low vapor pressures. For example, the maximum amount of $\mathrm{C}_{6}$-HPALD that could be evaporated into the 


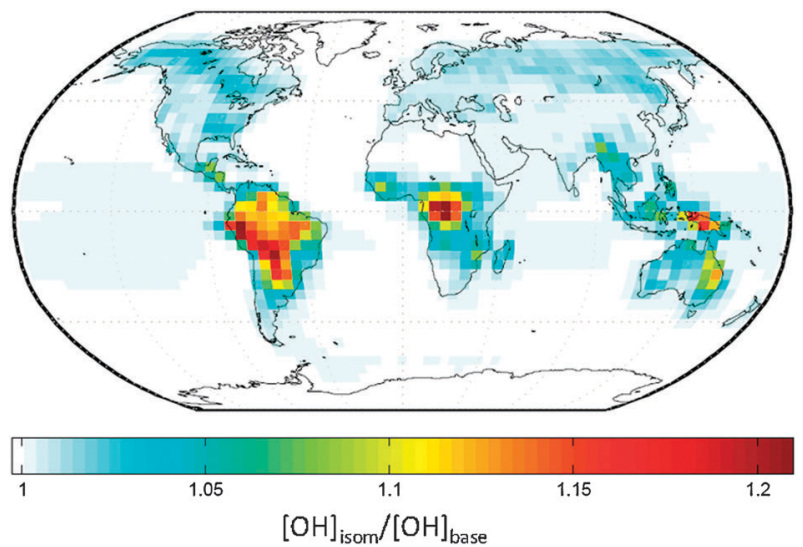

Fig. 7 GEOS-Chem simulated fractional change in boundary-layer $\mathrm{OH}$ concentrations resulting from the isomerization of isoprene peroxy radicals and the subsequent photolysis and $\mathrm{OH}$ oxidation of $\mathrm{C}_{5}$-HPALDs. An $\mathrm{OH}$ yield of 1 from $\mathrm{C}_{5}$-HPALDs photolysis is assumed. Results are averaged over one year. See text for model details.

reaction chamber ( $46.7 \mathrm{ppbv}$ ) suggests a vapor pressure on the order of $10^{-5}$ Torr for this compound. Given that isomerization can account for as much as $20 \%$ of the carbon flux in low-NO regimes, ${ }^{18}$ future work should also address the potential contribution of these oxidation products to organic aerosol growth.

\section{Acknowledgements}

This work was supported by the NOAA Climate and Global Change Postdoctoral Fellowship Program, administered by the University Corporation for Atmospheric Research. The authors thank NASA (NNX08AD29G), NSF (ATM-0934408 and ATM-0852406) and the Harvard University Center for the Environment for funding in support of this research. The authors also thank H. G. Kjaergaard for computation of ion-molecule collision rate parameters, M. Galloway for assistance with shipping logistics, and two anonymous reviewers for critical feedback on the manuscript.

\section{Notes and references}

1 M. Hallquist, J. C. Wenger, U. Baltensperger, Y. Rudich, D. Simpson, M. Claeys, J. Dommen, N. M. Donahue, C. George, A. H. Goldstein, J. F. Hamilton, H. Herrmann, T. Hoffmann, Y. Iinuma, M. Jang, M. E. Jenkin, J. L. Jimenez, A. Kiendler-Scharr, W. Maenhaut, G. McFiggans, T. F. Mentel, A. Monod, A. S. H. Prevot, J. H. Seinfeld, J. D. Surratt, R. Szmigielski and J. Wildt, Atmos. Chem. Phys., 2009, 9, 5155-5236.

2 A. Kiendler-Scharr, J. Wildt, M. Dal Maso, T. Hohaus, E. Kleist, T. F. Mentel, R. Tillmann, R. Uerlings, U. Schurr and A. Wahner, Nature, 2009, 461, 381-384.

3 I. J. George and J. P. D. Abbatt, Atmos. Chem. Phys., 2010, 10, 5551-5563.

4 A. T. Archibald, J. G. Levine, N. L. Abraham, M. C. Cooke, P. M. Edwards, D. E. Heard, M. E. Jenkin, A. Karunaharan, R. C. Pike, P. S. Monks, D. E. Shallcross, P. J. Telford, L. K. Whalley and J. A. Pyle, Geophys. Res. Lett., 2011, 38, L05804, DOI: 10.1029/2010GL046520.

5 A. Hofzumahaus, F. Rohrer, K. Lu, B. Bohn, T. Brauers, C.-C. Chang, H. Fuchs, F. Holland, K. Kita, Y. Kondo, X. Li, S. Lou, M. Shao, L. Zeng, A. Wahner and Y. Zhang, Science, 2009, 324, 1702-1704, DOI: 10.1126/science.1164566.
6 J. Lelieveld, T. M. Butler, J. N. Crowley, T. J. Dillon, H. Fischer, L. Ganzeveld, H. Harder, M. G. Lawrence, M. Martinez, D. Taraborrelli and J. Williams, Nature, 2008, 452, 737-740, DOI: $10.1038 /$ nature 06870 .

7 X. R. Ren, J. R. Olson, J. H. Crawford, W. H. Brune, J. Q. Mao, R. B. Long, Z. Chen, G. Chen, M. A. Avery, G. W. Sachse, J. D. Barrick, G. S. Diskin, L. G. Huey, A. Fried, R. C. Cohen, B. Heikes, P. O. Wennberg, H. B. Singh, D. R. Blake and R. E. Shetter, J. Geophys. Res. Atmos., 2008, 113, D05310, DOI: 10.1029/2003JD003551.

8 D. Tan, I. Faloona, J. B. Simpas, W. Brune, P. B. Shepson, T. L. Couch, A. L. Sumner, M. A. Carroll, T. Thornberry, E. Apel, D. Riemer and W. Stockwell, J. Geophys. Res. Atmos., 2001, 106, 24407-24427.

9 J. A. Thornton, P. J. Wooldridge, R. C. Cohen, M. Martinez, H. Harder, W. H. Brune, E. J. Williams, J. M. Roberts, F. C. Fehsenfeld, S. R. Hall, R. E. Shetter, B. P. Wert and A. Fried, J. Geophys. Res., 2002, 107, 4146-4163, DOI: 10.1029/ 2001JD000932.

10 G. M. Wolfe, J. A. Thornton, N. C. Bouvier-Brown, A. H. Goldstein, J.-H. Park, M. McKay, D. M. Matross, J. Mao, W. H. Brune, B. W. LaFranchi, E. C. Browne, K.-E. Min, P. J. Wooldridge, R. C. Cohen, J. D. Crounse, I. C. Faloona, J. B. Gilman, W. C. Kuster, J. A. de Gouw, A. Huisman and F. N. Keutsch, Atmos. Chem. Phys., 2011, 11, 1269-1294.

11 D. Stone, M. J. Evans, P. M. Edwards, R. Commane, T. Ingham, A. R. Rickard, D. M. Brookes, J. Hopkins, R. J. Leigh, A. C. Lewis, P. S. Monks, D. Oram, C. E. Reeves, D. Stewart and D. E. Heard, Atmos. Chem. Phys., 2011, 11, 6749-6771.

12 L. K. Whalley, P. M. Edwards, K. L. Furneaux, A. Goddard, T. Ingham, M. J. Evans, D. Stone, J. R. Hopkins, C. E. Jones, A. Karunaharan, J. D. Lee, A. C. Lewis, P. S. Monks, S. J. Moller and D. E. Heard, Atmos. Chem. Phys., 2011, 11, 7223-7233.

13 A. Guenther, T. Karl, P. Harley, C. Wiedinmyer, P. I. Palmer and C. Geron, Atmos. Chem. Phys., 2006, 6, 3181-3210.

14 G. da Silva, C. Graham and Z. F. Wang, Environ. Sci. Technol., 2010, 44, 250-256.

15 T. L. Nguyen, L. Vereecken and J. Peeters, ChemPhysChem, 2010, 11, 3996-4001.

16 J. Peeters and J. F. Müller, Phys. Chem. Chem. Phys., 2010, 12, $14227-14235$

17 J. Peeters, T. L. Nguyen and L. Vereecken, Phys. Chem. Chem. Phys., 2009, 11, 5935-5939.

18 J. D. Crounse, F. Paulot, H. G. Kjaergaard and P. O. Wennberg, Phys. Chem. Chem. Phys., 2011, 13, 13607-13613.

19 F. Paulot, J. D. Crounse, H. G. Kjaergaard, A. Kurten, J. M. St Clair, J. H. Seinfeld and P. O. Wennberg, Science, 2009, 325, 730-733.

20 T. Stavrakou, J. Peeters and J.-F. Müller, Atmos. Chem. Phys., 2010, 10, 9863-9878, DOI: 10.5194/acp-10-9863-2010.

21 D. Taraborrelli, M. G. Lawrence, J. N. Crowley, T. J. Dillon, S. Gromov, C. B. M. Groß, L. Vereecken and J. Lelieveld, Nat. Geosci., 2012, 5, 190, DOI: 10.1038/NGEO1405.

22 A. T. Archibald, M. C. Cooke, S. R. Utembe, D. E. Shallcross, R. G. Derwent and M. E. Jenkin, Atmos. Chem. Phys., 2010, 10, $8097-8118$.

23 W. D. Taylor, T. D. Allston, M. J. Moscato, G. B. Fazekas, R. Kozlowski and G. A. Takacs, Int. J. Chem. Kinet., 1980, 12, 231-240.

24 K. Sugamoto, Y. Matsushita and T. Matsui, J. Chem. Soc., Perkin Trans. 1, 1998, 23, 3989-3998.

25 L. S. Rothman, I. E. Gordon, A. Barbe, D. C. Benner, P. E. Bernath, M. Birk, V. Boudon, L. R. Brown, A. Campargue, J. P. Champion, K. Chance, L. H. Coudert, V. Dana, V. M. Devi, S. Fally, J. M. Flaud, R. R. Gamache, A. Goldman, D. Jacquemart, I. Kleiner, N. Lacome, W. J. Lafferty, J. Y. Mandin, S. T. Massie, S. N. Mikhailenko, C. E. Miller, N. Moazzen-Ahmadi, O. V. Naumenko, A. V. Nikitin, J. Orphal, V. I. Perevalov, A. Perrin, A. Predoi-Cross, C. P. Rinsland, M. Rotger, M. Simeckova, M. A. H. Smith, K. Sung, S. A. Tashkun, J. Tennyson, R. A. Toth, A. C. Vandaele and J. Vander Auwera, J. Quant. Spectrosc. Radiat. Transfer, 2009, 110, 533-572.

26 J. M. St. Clair, D. C. McCabe, J. D. Crounse, U. Steiner and P. O. Wennberg, Rev. Sci. Instrum., 2010, 81, 094102. 
27 A. L. Garden, F. Paulot, J. D. Crounse, I. J. Maxwell-Cameron and P. O. Wennberg, Chem. Phys. Lett., 2009, 474, 45-50.

28 T. Gierczak, J. B. Burkholder, R. K. Talukdar, A. Mellouki, S. B. Barone and A. R. Ravishankara, J. Photochem. Photobiol., A, 1997, 110, 1-10.

29 I. Magneron, R. Thevenet, A. Mellouki, G. Le Bras, G. K. Moortgat and K. Wirtz, J. Phys. Chem. A, 2002, 106, 2526-2537.

30 E. Jimenez, B. Lanza, E. Martinez and J. Albaladejo, Atmos. Chem. Phys., 2007, 7, 1565-1574.

31 M. P. O'Connor, J. C. Wenger, A. Mellouki, K. Wirtz and A. Munoz, Phys. Chem. Chem. Phys., 2006, 8, 5236-5246.

32 H. Keller-Rudek and G. K. Moortgat, MPI-Mainz-UV-VIS Spectral Atlas of Gaseous Molecules, www.atmosphere.mpg.de/spectralatlas-mainz, Accessed 03 March, 2012.

33 R. I. Olariu, B. Klotz, I. Barnes, K. H. Becker and R. Mocanu, Atmos. Environ., 2002, 36, 3685-3697.

34 R. Atkinson, S. M. Aschmann, W. P. L. Carter, A. M. Winer and J. N. Pitts, J. Phys. Chem., 1982, 86, 4563-4569.

35 R. Atkinson, Atmos. Environ., 2007, 41, 8468-8485.

36 R. Atkinson, D. L. Baulch, R. A. Cox, J. N. Crowley, R. F. Hampson, R. G. Hynes, M. E. Jenkin, M. J. Rossi and J. Troe, Atmos. Chem. Phys., 2006, 6, 3625-4055.

37 T. Brauers and B. J. Finlayson-Pitts, Int. J. Chem. Kinet., 1997, 29, 665-672.

38 F. Paulot, J. D. Crounse, H. G. Kjaergaard, J. H. Kroll, J. H. Seinfeld and P. O. Wennberg, Atmos. Chem. Phys., 2009, 9, 1479-1501.

39 J. D. Crounse, H. C. Knap, K. B. Ørnsø, S. Jørgensen, F. Paulot, H. G. Kjaergaard and P. O. Wennberg, J. Phys. Chem. A, 2012, DOI: $10.1021 / \mathrm{jp} 211560 \mathrm{u}$.
40 S. M. Saunders, M. E. Jenkin, R. G. Derwent and M. J. Pilling, Atmos. Chem. Phys., 2003, 3, 161-180.

41 K.-R. Hannelore and G. K. Moortgat, MPI-Mainz-UV-VIS Spectral Atlas of Gaseous Molecules, www.atmosphere.mpg.de/ spectral-atlas-mainz, Accessed December, 2011.

42 J. Peeters, W. Boullart, V. Pultau, S. Vandenberk and L. Vereecken, J. Phys. Chem. A, 2007, 111, 1618-1631.

43 L. Vereecken and J. Peeters, Chem. Phys. Lett., 2001, 333, 162-168.

44 M. E. Jenkin, S. M. Saunders and M. J. Pilling, Atmos. Environ., 1997, 31, 81-104.

45 N. Carslaw, D. J. Creasey, D. Harrison, D. E. Heard, M. C. Hunter, P. J. Jacobs, M. E. Jenkin, J. D. Lee, A. C. Lewis, M. J. Pilling, S. M. Saunders and P. W. Seakins, Atmos. Environ., 2001, 35, 4725-4737.

46 D. Stone, M. J. Evans, R. Commane, T. Ingham, C. F. A. Floquet, J. B. McQuaid, D. M. Brookes, P. S. Monks, R. Purvis, J. F. Hamilton, J. Hopkins, J. Lee, A. C. Lewis, D. Stewart, J. G. Murphy, G. Mills, D. Oram, C. E. Reeves and D. E. Heard, Atmos. Chem. Phys., 2010, 10, 9415-9429.

47 R. Commane, C. F. A. Floquet, T. Ingham, D. Stone, M. J. Evans and D. E. Heard, Atmos. Chem. Phys., 2010, 10, 8783-8801.

48 J. Mao, X. Ren, W. H. Brune, D. M. Van Duin, R. C. Cohen, J. H. Park, A. H. Goldstein, F. Paulot, M. R. Beaver, J. D. Crounse, P. O. Wennberg, J. P. DiGangi, S. B. Henry, F. N. Keutsch, C. Park, G. W. Schade, G. M. Wolfe and J. A. Thornton, Atmos. Chem. Phys. Discuss., 2012, 12, 6715-6744.

49 I. Bey, D. J. Jacob, R. M. Yantosca, J. A. Logan, B. D. Field, A. M. Fiore, Q. B. Li, H. G. Y. Liu, L. J. Mickley and M. G. Schultz, J. Geophys. Res. Atmos., 2001, 106, 23073-23095.

50 F. Paulot, D. K. Henze and P. O. Wennberg, Atmos. Chem. Phys., $2012,12,1307-1325$. 